\title{
Set up a coronary rehabilitation programme
}

\author{
H J N Bethell
}

Supervised rehabilitation for patients who are recovering from coronary illness or coronary surgery could and should be provided by every district general hospital. It would not be expensive to do so, but requires the hospital cardiologists and physicians to initiate, encourage, and nurture the programmes.

\section{Why do it?}

Coronary rehabilitation, which is popular in many Western countries, is not widely available in the United Kingdom. Although most cardiologists and general physicians support the concept, few are sufficiently interested to initiate rehabilitation programmes. Such treatment is, however, of great value in helping patients who have had an infarct or bypass graft to cope with the problems that face them. They are usually physically unfit, partly because few will have been taking regular exercise and partly because the period of rest necessary after the acute event produces further deconditioning. Patients are often depressed by the threat to their future and security and nearly always anxious about the chance of a recurrence. They suffer various symptoms such as "missed beats" and niggling left sided chest pains, which further undermine their battered self confidence. Angina or breathlessness may appreciably impair their exercise tolerance. A return to work provides an immense hurdle for many manual workers for whom a degree of physical fitness may be vital to the retention of their jobs.

Despite these difficulties most patients recover from their infarction or cardiac surgery and return to a reasonable level of functioning, though this is usually well below their optimal peformance. The rate of return to work of patients who have had coronary artery bypass is disturbingly low, and a substantial minority of patients who have had an infarct do poorly because of continued depression or anxiety. (Half of those who are not back at work six months after the attack are suffering from cardiac neurosis rather than physical disability.) A well organised rehabilitation programme can tackle all these problems and also provide a setting for other secondary preventive measures such as giving up smoking, changing the diet, and so on.

\section{What should be done?}

The core of coronary rehabilitation is physical training to ease the patient from inactivity back to full activity as quickly and safely as possible. Getting the patient mobilised early on in hospital and encouraging an optimistic attitude towards future physical capacity sets the scene, and this can be backed up by videos showing patients taking part in rehabilitation and by visits from former patients who have had this treatment.

Most patients are ready to start graduated exercise within three or four weeks of infarction and within five or six weeks of coronary artery surgery. The initial assessment includes taking a history, examining the patient, and taking a resting electrocardiogram. Patients who have increasing angina, heart failure, or uncontrolled arrhythmias should be sent back to their physician for further treatment. An exercise test should be carried out with electrocardiographic monitoring using either a treadmill or a bicycle ergometer. The treadmill provides an exercise to which the patient is accustomed, but it is expensive, noisy, and space consuming and some patients find it difficult to balance on one. The bicycle is cheap and easy to operate and allows blood pressure to be measured accurately during the test but requires the patient to keep a constant pedalling rate. It is usual to take the patient up to $85 \%$ of his or her predicted maximum heart rate or to level 5 or 6 on the Borg scale for those who are taking $\beta$ blockers, unless stopped by angina, excessive breathlessness, falling blood pressure, or complex arrhythmias. (The Borg scale is a scoring system for perceived exertion, which runs from 0.5 (very, very light) to 10 (very, very heavy) and which has been shown to have a good correlation with heart rate response to exercise.) Problems arising during the test may indicate the need for further treatment before starting exercise. The test measures the present fitness level from which the exercise prescription can be devised and against which future performance can be compared.

The exercises used should be dynamic or "aerobic" - that is, entailing much movement without emphasising power. Such exercise raises the heart rate and systolic blood pressure and produces breathlessness. Isometric exercise involves strength rather than movement, raises both systolic and diastolic pressure without great effect on the heart rate, and has much less effect on aerobic fitness which is so desirable for the coronary patient. The most popular regimen in Britain is circuit training using various exercises such as stationary cycling, stepping up and down, jogging on a minitrampoline, and a mix of arm and leg exercises with light dumb bells. This is easy to supervise in a small area and needs little equipment. The variety provided by a circuit is less boring than single exercise sessions, reduces the risk of musculoskeletal injuries, and prepares the patient for many different activities at work and leisure. Some centres do rely on a single exercise such as cycling or jogging and find it satisfactory. A warm up routine with calisthenics is important and a warm down with non-competitive games may enjoyably round up the session.

The training sessions should ideally be held three or four times a week (but twice a week will suffice), last 20 to 30 minutes, and increase the heart rate to between $70 \%$ and $85 \%$ of the patient's predicted maximum ( $85 \%$ of the predicted maximum heart rate is roughly 195 minus the age) or to a lower heart rate if indicated by the exercise test-in patients taking $\beta$ blockers or with angina. This regimen has been shown to be optimal for producing a good increase in fitness; more frequent, prolonged, or intensive exertion gives little further benefit but carries an increased risk of musculoskeletal injuries or undesirable cardiac arrhythmias. The patient starts with a very light circuit and this is increased gradually in number and speed of repetitions in response to the heart rate reached at the previous session. It is helpful to encourage the spouse to join in the training programme, giving him or her an insight into the patient's exercise capacity, thus reducing
Health Centre, Alton, Hants GU34 2QX H J N Bethell, MRCGP, general practitioner 


\section{Coronary rehabilitation}

Why?

Patients:

- unfit

- anxious

- functioning below optimal level

- angina/breathlessness Secondary prevention

\section{When?}

Start:

- 3-4 weeks after myocardial infarction

- 5-6 weeks after coronary artery surgery

Sessions 20-30 minutes 2-4 times a week for 6-12 weeks

Continue exercise at home

"mollycoddling" at home and encouraging compliance. Within two or three weeks home exercise should be started since wholly supervised sessions encourage dependence and a high dropout rate once the course is over. The home sessions can include a circuit similar to the supervised ones using $3 \mathrm{~kg}$ dumb bells for arm and leg movements, jogging on the spot, and stepping up and down two steps. Many patients have or can borrow a static bicycle or rowing machine which may be incorporated into the circuit. The heart rate before and after exercise and the time taken to complete the exercise are recorded so that logical progression can be worked out. A daily brisk walk over a measured distance of one to two miles recording the same observations is a useful extra and in fitter patients can be increased to a jog within a few weeks.

The length of the course must depend on local resources and the number of patients presenting for treatment. Six to 12 weeks is usual-it is long enough to increase fitness moderately and to start the patient on the road to continued unsupervised exercise as part of the way of life. This duration must be flexible to allow for those with little heart damage who progress very quickly and for those with cardiac or psychological problems who need much more careful nurturing through the proramme. A final exercise test to measure the fitness level attained can be followed by the long term exercise prescription.

\section{Who should do it and where?}

There is no reason why every district general hospital in Britain should not provide this facility for patients after an infarct or coronary artery surgery. A cardiologist or general physician who is interested in cardiac rehabilitation would be the most suitable person to organise it. In most hospitals, however, there is no one who is sufficiently motivated to do it, which explains why there are so few programmes. In several hospitals a nurse or physiotherapist has initiated a rehabilitation course which has then been supported with more or less enthusiasm by the doctors. Each district general hospital serves a population of several hundred general practitioners, and where it is not possible to find a member of the hospital staff to do it it should be easy to find a local general practitioner to take it on. The general practitioner would usually need to be recruited by the hospital, though some might initiate programmes themselves.

There is no course of instruction in Britain for would-be cardiac rehabilitators. Some necessary areas of knowledge include coronary heart disease, exercise physiology, exercise testing, the special problems of exercise in coronary patients, and resuscitation. Most people who are interested in this subject will have experience in some of these disciplines, but most will need to extend their education by visiting existing programmes, cardiac departments, and exercise laboratories and by reading (a suggested reading list is given at the end of this paper).

The physiotherapy department is the obvious place for holding courses in hospital. Outside hospital com- munity sports centres provide the ideal site. Not only do they have more space than most hospitals but they also have much of the appropriate equipment for circuit training, often including bicycle ergometers, and have staff well experienced in using it. An added advantage of exercising at sports centres is that it encourages a return to normal. The patient going to the sport centre is having fun rather than treatment, and this should encourage compliance and in the long term lead to a habit of regular exercise.

\section{What does it cost?}

The minimum equipment includes a defibrillator and oscilloscope (c $£ 3000$ ), one or two bicycle ergometers (c $£ 400$ each), and a few exercise accessories such as dumb bells, barbels, two step climbs, and minitrampolines (not more than £300). For hospital courses only the exercise equipment will need to be bought. The defibrillator and oscilloscope provides the main financial hurdle for the programme outside hospital, but these can often be borrowed from the hospital. Public interest in community coronary rehabilitation makes it easy to raise charitable funds for equipment.

The Basingstoke District Hospital course employs two hospital practitioner sessions ( $\$ 3700$ a year), a sports officer for three hours a week ( $\$ 707$ a year), and a physiotherapist for three hours a week ( $\$ 877$ a year), giving a total of $£ 5284$ a year. About 100 patients are treated each year, making the cost per rehabilitated patient $£ 53$, less than the cost of half a day in hospital.

\section{What else should be done?}

Patients who are recovering from heart attacks or heart surgery have needs beyond simply regaining physical fitness. They are usually anxious to take all possible steps to reduce the chance of further coronary problems, and they gratefully embrace all approaches which may help. Most will have given up smoking in the coronary care unit, but those who have not will need help. Dietary advice to help reduce weight and where appropriate to reduce blood fat concentrations should be provided. Teaching patients about the nature of coronary heart disease, its risk factors, symptoms, and logical management helps them to understand their condition and to work for their own good health. The group therapy effect of the rehabilitation sessions, which provide the opportunity for patients to meet and discuss mututal difficulties, makes it easier for them to cope with minor problems. Severe tension, anxiety, and depression, which may not readily be admitted, need to be recognised and will often require professional treatment. Ideally, counselling and management of stress, and later on help with the return to work, should be available. Finally, once the patients have finished the supervised rehabilitation it should be easy for them to continue to exercise, preferably as a group. Organising a self help club of graduates of the course is the best way of catering for their need for exercise, social support, and recreation.

\section{Further reading}

Andersen EL, Shephard RJ, Denolin H, Varnauskas E, Masironi R. Fundamental of exercise testing. Geneva: World Health Organisation, 1971. Astrand P-O, Rodahl K. Textbook of work physiology. New York: McGraw-Hill, 1976.

Clausen JC. Effect of physical training on cardiovascular adjustments to exercise in man. Physiol Rev 1977;57:779-815.

Joint Working Party of the Royal College of Physicians of London and the British Cardiac Society. Cardiac rehabilitation 1975. I $R$ Coll Physicians Lond 1975;9:281-346.

Scientific Council on Rehabilitation of Cardiac Patients. Myocardial infarction

How to prevent. How to rehabilitate. International Society and Federation of How to prevent. Hon

Shephard RJ. Ischaemic heart disease and exercise. London: Croom Helm, 1981. Wenger NK, Hellerstein HK, eds. Rehabilitation of the coronary patient. New
York: Wiley, 1978 . 